\title{
Medical Students Satisfaction from Peer Advising in an Integrated Problem Based Learning Curriculum: A Cross Sectional Study
}

\author{
Amer Al Homssi, Tayseer Shamaa, Mousa Abu Ghoush, Nawar Alhourani, Hadeel Awad, Mohamad Al-Akchar \\ and Hossam Hamdy \\ College of Medicine, University of Sharjah, Sharjah 27272, United Arab Emirates
}

\begin{abstract}
To evaluate the satisfaction of medical students from Students Peer Advising activities, its strengths, limitations and how it can improve. Students Peer Advising (SPA) was initiated by students in order to support collaborative and experiential learning. In this approach, senior students provided and shared their educational experiences with junior students individually or in large groups. Advice was mainly on how to succeed in this demanding student centered educational program. Two groups were investigated, the committee members (Advisors) and the students (Advisees) who attended the SPA events, by using a self-administered questionnaire. One hundred and thirteen advisees responded. 74 (65\%) advisees provided a score of 4 or 5 out of 5 , with 5 being the most satisfactory and useful, when inquired about the overall satisfaction and usefulness of peer advising. SPA committee consisted of fifteen members, of whom thirteen responded. Fifteen sessions were conducted by members from different academic years, and they all agreed that it was a beneficial experience. The most rewarding aspect of their experience revolved around the gratification and sense of satisfaction consequent to improving the students' academic performance. The study found that peer advising was appreciated by students and peer advisors.
\end{abstract}

Key words: Students Peer Advising, Peer Advising Committee, College of Medicine, University of Sharjah.

\section{Introduction}

Students view the curriculum through a different lens than do faculty and are more familiar with the student experience and how they learn. Peers can better relate and respond to students' concerns as they went through the same experiences. Students connect easier to other students and freely share their experience and knowledge. They consider discussing their difficulties with other students valuable and easier.

Interest in peer-teaching also commonly known as Peer-Assisted learning (PAL) is growing in the field of medical and allied health education [1]. In theory, advocates of peer-teaching and PAL suggest that its success lies in the fact that peer-teachers share a

Corresponding Author: Amer Al Homssi, M.D., research fields: medical education, epigenetics and cancer. similar knowledge base and learning experience of their peers "cognitive congruence", which allows the peer-teachers to use language that their peers understand and to explain concepts at an appropriate level [2].

There is a substantial list of documented qualitative benefits that originate from peer-teaching strategies in the setting of health professional education. It includes enhanced cognitive, psychomotor and affective development of students participating in this collegial collaborative behavior [1].

In the United Kingdom, acknowledgment of peer-teaching and its associated benefits has been formally expressed by the General Medical Council (GMC) whose statement maintains that medical graduates must "be able to demonstrate appropriate teaching skills" [3], and in the United States, interest in peer-teaching and PAL has also been recognized. 
Survey in large number of medical schools utilized their medical students in some form of peer-teaching during the medical program [4].

The College of Medicine, University of Sharjah adopts a competency based, integrated curriculum. The main strategy of learning is problem-based combined with team based learning [5]. The curriculum consists of carefully selected and designed problems that lead to acquisition of relevant knowledge, problem-solving proficiency, self-directed learning strategies, and teamwork. The process replicates the commonly used systematic approach to resolving problems or meeting life's challenges [6].

The 5-year curriculum is divided into 2 phases. In Phase I (years 1, 2 and 3), it is integrated and organized into "units" each dealing with a major body system (e.g., Cardiovascular, Renal, etc.). The units range in length from 4 to 12 weeks duration. In this phase, PBL underpins all teaching and learning. One problem is studied every week over two sessions each of $2 \mathrm{~h}$. This phase is followed by a clerkship phase of 2 years structured around clinical rotations in different clinical disciplines [7].

Students Peer Advising (SPA) started as a student initiative in order to improve the cooperation between junior students and senior students, share seniors' educational experiences and contribute to their colleges' professional development. Moreover, knowing that there are students who had difficulties which they may be able to help in overcoming it could be a rewarding.

SPA started in its first year with six students from the 2nd and 4th years. In the subsequent years, more students were accepted to be members of the SPA committee after an interview to explore their motivation, expectations and commitment reaching a total of nineteen members.

The SPA activities were divided into two types. Individual peer advising was mainly conducted through social media (Facebook, Twitter and emails) and face-to-face meetings in the college. Large groups' advising was conducted through scheduled sessions at the beginning of every semester to orient the students in each year to their respective curriculum, organ system units, clerkship rotations, problems which they may encounter and how to safely navigate and succeed. Other sessions were offered which included examination preparation tips and studying strategies in the PBL curriculum and in the clerkship.

Prior to each SPA session, live and online announcements were made about its location and timing. The general theme, content and delivery method of the group advising presentations were derived from experiences of the senior students. The contents of the sessions and type of experiences to be communicated to the students were discussed among the committee in order to agree on the points to be shared with the students. The activities scheduling and content were coordinated and communicated in advance of the session by using Facebook and WhatsApp.

The aim of the study is to evaluate the satisfaction of medical students "advisee" and "advisors" from the peer advising activities, identify its strength, limitations and areas for improvement.

\section{Methodology}

In order to investigate the effectiveness of the SPA initiative, an observational cross-sectional study was conducted investigating the satisfaction of the SPA committee members and the students who attended the advising sessions. A self-administered questionnaire was developed adapting a validated available questionnaire [8, 9]. The advisees' questionnaire aimed to collect information about the students' demography, type of activities, reflection on experience and impact of the peer advising activities. The advisors' questionnaire evaluated the same domains with the addition of professional qualities acquired by going through the experience. The questionnaires were sent via email to all students in the pre-clerkship years who attended the SPA sessions. 
The fixed response questions were assessed using a five-point likert scale. Open-ended questions were analyzed using a qualitative approach "identifying the evolving themes".

\section{Results and Discussion}

\subsection{Responses from Advisees}

Two hundred students received the questionnaire. One hundred and thirteen students responded giving a response rate of $60 \%$.

Regarding the number of sessions attended by the advisees, up to 2 sessions were attended by 43 (38\%), 3 sessions were attended by 42 (37\%) and 4 to 5 sessions were attended by 28 (25\%). When inquired about the overall satisfaction and usefulness of peer advising, 74 (65\%) of the students found that it was useful and satisfactory.

On the other hand, 26 (23\%) of the students who attended the sessions indicated that these sessions were not organized, insufficient in terms of content and frequency, or some of the advisors were not competent enough to meet the objectives of the session.

When asked about student challenges which SPA can tackle, student responses included: "the need to advise advisees about how to study certain subjects and get through the exams", "How to organize a studying schedule throughout the year. What to study? How to study in terms of teams independently (Table 2).

The summary of responses regarding the effectiveness of the sessions provided is listed in Table 3.

\subsection{Responses from the Advisors}

SPA committee consisted of 15 members, of whom 13 responded, two from year 1, two from year 2, six from year 3, one from year 4, and two from year 5 . Eight members were females, and five were males. Seven are from a British-based schooling system, two from UAE-based system and three from American-based system.

Table 1 Gender and academic year of the respondents.

\begin{tabular}{lcc}
\hline Gender & & Academic Year \\
\hline Males & Year 1: $17(15.0 \%)$ & Year 3: $14(12.4 \%)$ \\
$\mathrm{N}=45(40 \%)$ & Year 2: $13(11.5 \%)$ & Year 4: $1(0.80 \%)$ \\
Females & Year 1: $19(16.8 \%)$ & Year 3: 23 (33.8\%) \\
$\mathrm{N}=68(60 \%)$ & Year 2: 25(22.1\%) & Year 4: 1 $(0.80 \%)$ \\
\hline
\end{tabular}

Table 2 The challenges faced by students that SPA can help with.

\begin{tabular}{ll}
\hline Advisees challenges & Number of responses \\
\hline Guidance for studying strategies & $26(38 \%)$ \\
Time management & $25(36 \%)$ \\
Finding proper resources & $15(22 \%)$ \\
Future plans & $3(4 \%)$ \\
\hline
\end{tabular}

Table 3 The effectiveness that SPA sessions had on the different aspects of the academic life of the students.

\begin{tabular}{ll}
\hline Aspects covered during sessions were effective & Advisee Responses \\
\hline The topics were relevant to the students & $81(71 \%)$ \\
Enhancement of board exams preparation & $74(65 \%)$ \\
Exam preparation skills improvement & $64(56 \%)$ \\
Studying strategies improvement & $62(54 \%)$ \\
Development of better coping mechanisms & $57(50 \%)$ \\
Students' encouragement for study groups & $49(43 \%)$ \\
Final grades enhancement & $48(42 \%)$ \\
Time-management skills improvement & $41(36 \%)$ \\
\hline
\end{tabular}


Fifteen sessions were conducted by members from different academic years, and they all agreed that it was a beneficial experience. According to the feedback collected from the advisors, the most rewarding aspect of their experience revolved around the gratification and sense of satisfaction consequent to improving the students' academic performance, as mentioned by some advisors:

"This committee allowed me to satisfy my dream of helping others and telling them more about the best ways of tackling different difficulties in my studies". "This is an excellent chance for me to have an extracurricular activity that is relevant to studies while not feeling that I am wasting my time"; and "PAC gave me the chance to polish my skills and at the same time to benefit others".

On the other hand, some of the challenges faced by the advisors included balancing between the demands of peer advising and the personal academic performance. Difficulty in expressing ideas and convincing others is lacking the experience to satisfy all the needs of the students.

Ten (80\%) of the SPA members noticed improvement in the following professional skills: communication, team work, cooperation, leadership, presentation, learning from other experiences and developing positive attitude towards helping others (Table 4). These skills were acquired and enhanced through planning and establishing the advisory committee, the preparation for the sessions, and the discussions amongst the members.

SPA is a supportive strategy in the fuzzy world of academic advising. While it does not replace faculty advising, peer advising can complement other advising systems. The advantages of using peer advising include flexibility in delivery methods, peer-to-peer trustful interaction and professional development of the advisers. A concern in implementing SPA program is the time and energy involved, in addition to the academic and personal responsibilities bestowed on the advisors themselves [10]. However, the overall benefits of peer advising far outweigh the potential drawbacks, thus institutions should encourage such initiatives as it improves students retention rates and enhance the student experience [11, 12].

The findings of our research match the core reasons stated by Diambra [13] behind the implementation of a peer advising program which involved: bridging the gaps between learning, and advising, student recruitment, and a sense of connection through similar experiences. The benefits gained by the advisers included: developing communication skills, practicing leadership outside the classroom and experiencing a professional behavior at an early phase of their career. SPA was a new experience to the medical students of University of Sharjah which can be the reason behind an insufficiently high response rate.

Peer Advisors provided useful academic support and facilitated on-campus involvement with students [9]. In an earlier study, Russel and Skinkle [14] examined a peer-advising orientation program and found that participation in the program enhanced students' sense of membership in the university community.

Table 4 Percentage of members who agree that their different professional qualities were enhanced by being part of SPA.

\begin{tabular}{ll}
\hline Professional qualities improved by being part of SPA & Advisors responses \\
\hline Learning from others' experiences & $12(93 \%)$ \\
Linking between new years & $11(86 \%)$ \\
Leadership skills & $11(86 \%)$ \\
Positive attitude towards helping others & $11(86 \%)$ \\
Development of better coping mechanisms & $11(86 \%)$ \\
Presentation skills & $10(79 \%)$ \\
Working as part of a team & $10(79 \%)$ \\
Communication skills & $10(79 \%)$ \\
\hline
\end{tabular}


This study investigated the effectiveness of SPA as perceived by students whether Advisee or Advisor. Effectiveness of SPA at high levels, influencing behavior and performance are lacking. Peer advising programs are increasingly more effective, but evident research gaps still exist. Peer advising programs need to be structured, carefully planned, provide training, and continuously evaluate themselves [15].

\section{Conclusions}

The study found that peer advising was a successful experience for both advisers and advisees in the College of Medicine, University of Sharjah. The suggestions provided by participants should be taken into consideration and to be applied with the expansion of SPA.

\section{Acknowledgments}

The authors of this paper would like to thank the students and all members of SPA for their sincere contribution in making the SPA committee a success.

\section{References}

[1] Tzu-Chieh, Y., Wilson, N. C., Singh, P. P., Lemanu, D. P., Hawken, S. J., and Hill, A. G. 2011. "Medical Students-as-teachers: a Systematic Review of Peer-assisted Teaching during Medical School.” Advances in Medical Education and Practice 2: 157-72. doi: 10.2147/AMEP.S14383.

[2] Cornwall, M. G. 1980. Students as Teachers: Peer Teaching in Higher Education. Amsterdam: Centrum Onderzoek Wetenschappelijk Onderwijs.

[3] GMC 2009. Tomorrow's Doctors: Recommendations on Undergraduate Medical Education. London: General Medical Council.

[4] Soriano, R. P., Blatt, B., and Coplit, L., et al. 2010. “Teaching Medical Students How to Teach: a National Survey of Students-as-teachers Programs in US Medical
Schools." Acad. Med. 85 (11): 1725-31. doi: 10.1097/ACM.0b013e3181f53273.

[5] Hamdy, H. 2008. "The Fuzzy World of Problem based Learning.” Med. Teach 30 (8): 739-41. doi: 10.1080/01421590802345891.

[6] Kilroy, D. A. 2004. "Review-Problem based Learning." Emergency Medical Journal 21: 411-3. doi: 10.1136/emj.2003.012435.

[7] Hamdy, H., and Agamy, E. 2011. "Is Running a Problem-Based Learning Curriculum more Expensive than a Traditional Subject-Based Curriculum?” Med. Teach $33 \quad$ (9): e509-14. doi: 10.3109/0142159X.2011.599451.

[8] Cuseo, J. 2012. "Assessment of Academic Advisors and Academic Advising Programs.” Accessed June 1, 2014. http://uwc.edu/sites/uwc.edu/files/imce-uploads/employe es/academic-resources/esfy/_files/assessment_of_academ ic_advisors_and_academic_advising_programs.pdf.

[9] Rae, L. 2004. "Evaluation of Training and Learning." Accessed February 22, 2014. http://www.businessballs. com/trainingevaluationtools.pdf.

[10] Gordon, V. N., Habley, W. R., and Grites, T. J. 2008. Academic Advising: A Comprehensive Handbook. San Francisco, CA: Jossey-Bass.

[11] Kuba, S. E. 2010. "The Role of Peer Advising in the First-year Experience.” Doctoral Dissertation, University of Wisconsin-Madison, Madison, WI.

[12] Swisher. E. 2013. "Practical Considerations in Developing Peer Advising Programs.” Indiana University-Purdue University Indianapolis. Accessed June 1, 2014.http://dus.psu.edu/mentor/2013/03/considerations-p eer-advising-programs/.

[13] Diambra, J. F. 2003. "Peer Advising: An Opportunity for Leadership and Competency Development.” Human Service Education 23 (1): 25-37.

[14] Russel, J. H., and Skinkle, R. R. 1990. "Evaluation of Peer-adviser Effectiveness.” Journal of College Student Development 31 (5): 388-94.

[15] Guadiana, L. 2013. "Effectiveness of Peer Advising Programs on College Campuses.” Accessed June 1, 2014. http://www.craftonhills.edu/ /media/Files/SBCCD/CHC/ About\%20CHC/Research\%20and\%20Planning/Research \%20Briefs/Academic\%20Success\%20Studies/1314_Peer AdvisingReview.pdf. 